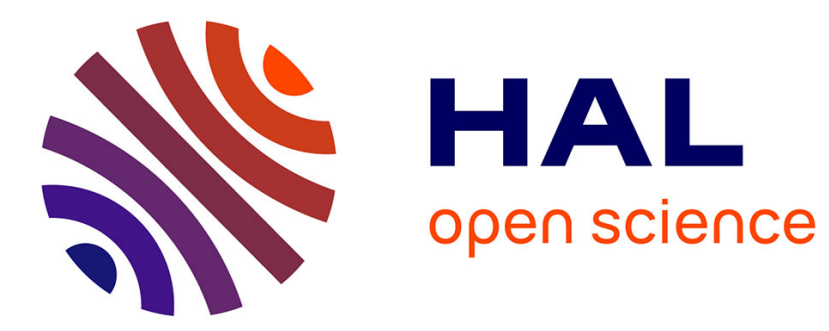

\title{
Express-Control of Superconducting Microcircuits Technology by Anodization Spectroscopy Method
}

\author{
T. Lebedeva, S. Navala, P. Shpilevoy, I. Vojtovich
}

\section{To cite this version:}

T. Lebedeva, S. Navala, P. Shpilevoy, I. Vojtovich. Express-Control of Superconducting Microcircuits Technology by Anodization Spectroscopy Method. Journal de Physique IV Proceedings, 1996, 06 (C3), pp.C3-403-C3-408. 10.1051/jp4:1996361 . jpa-00254279

\section{HAL Id: jpa-00254279 https://hal.science/jpa-00254279}

Submitted on 1 Jan 1996

HAL is a multi-disciplinary open access archive for the deposit and dissemination of scientific research documents, whether they are published or not. The documents may come from teaching and research institutions in France or abroad, or from public or private research centers.
L'archive ouverte pluridisciplinaire HAL, est destinée au dépôt et à la diffusion de documents scientifiques de niveau recherche, publiés ou non, émanant des établissements d'enseignement et de recherche français ou étrangers, des laboratoires publics ou privés. 


\title{
Express-Control of Superconducting Microcircuits Technology by Anodization Spectroscopy Method
}

\author{
T.S. Lebedeva, S.Ya. Navala, P.B. Shpilevoy and I.D. Vojtovich \\ Lyatoshinskogo st. 26" б", fl.4, 252191 Kiev, Ukraine
}

\begin{abstract}
Results of investigation of anodization process in thin-film microelectronic structures are presented. Anodization spectroscopy method, a new high-resolution way of studying films and thin-film structures, is developed for the express-control of superconducting microcircuits technology based on niobium and aluminium. The performed rapid analysis enables to control efficiently and to correct the technological process and make it possible to estimate the quality and output parameters of fabricated microcircuits. The new method is represented for measuring the size departure in cryoelectronic elements during etching and anodizing of edges directly in the process of microcircuits manufacture.
\end{abstract}

\section{FOUNDATION OF THE METHOD}

It is well known that at anodic oxidization of the metals in the constant-current method an increment in the thickness of the oxide layer is followed by the growth of voltage on the electrolytic cell. The growth rate of the oxide layer thickness is

$$
d x / d t=\lambda(M / n Z \rho F) j,
$$

the rate of the voltage change on the oxide layer is

$$
d U / d t=\lambda(M / n Z \rho F) j E_{d i f},
$$

where $\mathrm{j}$ is the current density, $M$ is a molecular mass of the oxide, $p$ is an oxide density, $n Z$ is a valency of oxidation reaction, $F$ is Faraday constant, $\lambda$ is the chemical efficiency, $E_{\mathrm{dif}}=\mathrm{dU} / \mathrm{dx}$ is the differential field strength in the oxide.

Under anodization at constant current the current density $j=U / S$, where $I$ is a stabilized current through the electrolytic cell, $S$ is an area of the anodization front. Each change of the anodization area results in the change in current density and dU/dt. This fact makes possible the investigation of the relief of the anodization front. When the metals for wich $\lambda=1$ are oxidizing, $\mathrm{dU} / \mathrm{dt}$ is constant during the entire anodization process. In this case the thickness of anodized metalic layer can be easily determined by formula $d_{m e}=\Delta \cdot K_{m e}$ where $K_{o x}$ is a general voltage appearing on the oxide layer after anodization, $K_{m e}$ is an anodization constant for the given metal. The thickness of the anodic oxide is calculated from $\mathrm{d}_{\mathrm{ox}}=\Delta \cdot \mathrm{K}_{\mathrm{ox}}$ where $\mathrm{K}_{\mathrm{ox}}$ is an anodization constant for the given oxide. Changing $\mathrm{dU} / \mathrm{dt}$ under the anodization will mean either the change of molecular volume of the oxide, or the change of $E_{d i f}$ or appearence of some side reaction deminishing the efficiency of oxidation. 
The abovesaid was the basis for creation of the method of anodization spectroscopy for multilayer thin film structures. It consists in the fact that according to the character of change of $\mathrm{dU} / \mathrm{dt}(\mathrm{t})$ or $\mathrm{dU} / \mathrm{dt}(\mathrm{U})$, which is more illustrative, one can judge the presence heterogeneition in the metal on the path of the anodization front, the change in composition of the oxide layer, the thickness and composition of metalic and dielectrical layers being a part of the state of the layers boundaries.

As the analysis of bibliography [1-7] has shown that the method has a high depth resolution ( $0.5 \mathrm{~nm}-$ $0.01 \mathrm{~nm}$ ). It requires noexpensive equipment and no long time to carry out the analysis. The method of anodization spectroscopy can be used to estimate output parameters of thin-film Josephson junctions directly in the preparation process [2-8]. It can be a simple and reliable method of the express-analysis in the development of thin-film technology conditions.

\section{INVESTIGATION TECHNIQUE}

The methods for locating the area under investigation which give a high stability of the current density during anodization are developed. With the insulating substrate, the configuration of the investigated 1 $\mathrm{mm}^{2}$ area in the form of a "flag" was obtained by liquid etching. With the conducting substrate a photoresist mask was used. The mode of working voltages in locating the area by the "flag" is limited only by the break-down voltage of the anodic oxide proper and amounts to $160 \mathrm{~V}$, when using the photoresist is no more that $100 \mathrm{~V}$, it is limited by photoresist break-down. Anodization was performed by the "drop" method at constant current with density $1 \mathrm{~mA} / \mathrm{cm}^{2}$.

\section{RESULTS}

\subsection{Investigation of Distribution the Thickness of Films Over the Substrate.}

We investigated the distribution of the thickness of deposited films over the substrate using the method of anodization spectroscopy. It was done with the purpose of studying the distinctive features of operation of magnetron systems with different design as well as for choosing the region of constant thickness of films. The regions of constant thickness of $\mathrm{Nb}$ and $\mathrm{Al}$ do not coincide because of different position of magnetrons for $\mathrm{Nb}$ and $\mathrm{Al}$ deposition about a substrate holder. Only the region where deviation of the thickness of both $\mathrm{Nb}$ and $\mathrm{Al}$ does not exceed $5 \%$ satisfies conditions necessary for fabrication of Josephson microcircuits with the admissible spread of parameters over the substrate. It is in this region of the substrate holder determined by anodization spectroscopy method that we used for fabrication of work microcircuits.

\subsection{Investigation of Roughness of Films and Substrates}

Since $\mathrm{dU} / \mathrm{dt}$ is inversely proportional to the area of the anodization front it is naturally to assume that the initial minimum on anodization profile is connected with enlarged square which depends upon roughness of the surface at the initial moment of oxidation. When anodization proceeds the area of the anodization front is levelled since due to the heterogeneity of electrical field on the rough surface and resulting redistribution of the current density the surface convexities are anodized first of all. The conducted investigations have shown that the given technique makes possible the estimation of the degree of film roughness by the value of the initial minimum of anodization profile. The roughness of niobium films is found to depend upon the way and conditions of deposition. With magnetron deposition it amounts be $1 \mathrm{~nm}$ when the argon pressure during deposition amounts to $0.4 \mathrm{~Pa}$ and twice as much at $1.3 \mathrm{~Pa}$. 


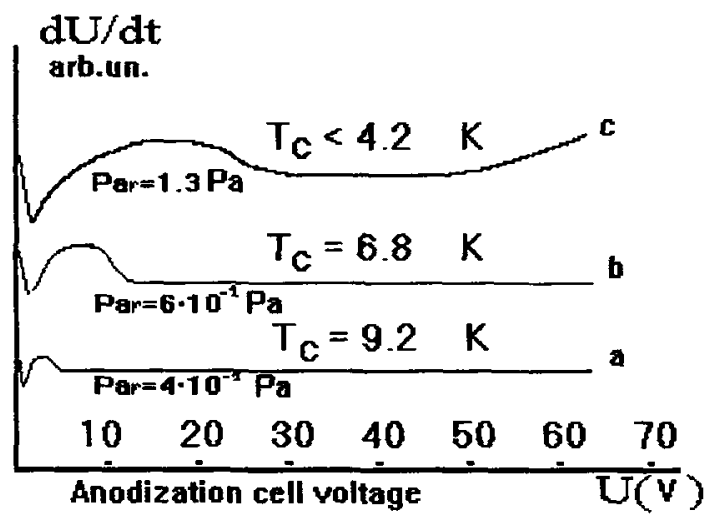

Figure 1. Anodization profiles of niobium films deposited by magnetron at various conditions: $\mathrm{a}-\mathrm{P}_{\mathrm{ar}}=0.4 \mathrm{~Pa} ; \mathrm{b}-\mathrm{P}_{\mathrm{ar}}=0.6 \mathrm{~Pa} ; \mathrm{c}-\mathrm{P}_{\mathrm{ar}}=1.3 \mathrm{~Pa}$
The roughness of substrates was estimated by a section of anodization profile corresponding to the film substrate boundary. For the used substrates of the oxidized silicon it did not exeed $5 \mathrm{~nm}$, for sital substrates $-10 \mathrm{~nm}$. It has been found that the working of niobium with the etching agent in the process of direct photolythography with chemical etching of microstructures insignificantly changes the roughness of substratas of oxidized silicon while the roughness of sital increases up to $1 \mu \mathrm{m}$ and more. That is why it is necessary to use of lift off photolythography on sital substrates in cases when the deposition of subsiquent smooth layers is required.

\subsection{Investigation of Niobium Films Deposited by Magnetron Sputtering at Different Argon Pressures.}

Investigation of superconducting properties of niobium films obtained by magnetron deposition [5,7] have shown that the temperature of their transition to the superconducting state $\left(T_{c}\right)$ depends upon the pressure of argon (Fig.1). The chamber was preliminary pumped to $\mathrm{P}=2.5 \cdot 10^{-5} \mathrm{~Pa} .99 .9 \%$ - purity argon was used. At $P_{A r}=4 \cdot 10^{-1} \mathrm{~Pa}$ the films have $T_{c}=9.2 \mathrm{~K}$. With the increase of pressure to $P_{\mathrm{Ar}}=6 \cdot 10^{-1} \mathrm{~Pa}$ the transition temperature was decreased to $T_{c}=7.8 \mathrm{~K}$. Films deposited at $P_{A r}=1.3 \mathrm{~Pa}$ and above did not transit to superconducting state in liquid helium without pumping $\left(\mathrm{T}_{6}<4.2 \mathrm{~K}\right)$. Electron microscopy and $\mathrm{X}$ ray examinations of these films have shown that with the increase of argon pressure in depositing the porosity of films and roughness of their surface increase [4,5]

Near-surfase maximum on the anodization profiles of niobium films are connected, in our opinion, with penetration of atmospheric oxigen in the upper layer of the film and with formation of different forms oxide-niobium compounds. For films with dense structure deposited at $\mathbf{P}_{\mathrm{Ar}}=4 \cdot 10^{-1} \mathrm{~Pa}$ (Fig. 2,a) nearsurfase properties terminate at voltage near $5 \mathrm{~V}$, which corresponds to the thickness of enriched with oxigen layer 4-5 nm. This results is in good agreement with literature data. For films deposited at $\mathbf{P}_{\mathrm{Ar}}=1.3$ $\mathrm{Pa}$ (Fig. 2, C) the range with a high oxigen content extends to $25-30 \mathrm{~nm}$. Besides, the increase in the rate of voltage growth in depth is observed which grows as they approach the substrate. This increase is connected with the presence of impurities in the film which were gettered in the process of condensation. The above effects become more explicit with decreasing the evaporation rate.

\subsection{Investigation of Multilayer Structures Based on Niobium and Aluminium}

Results of investigating $\mathrm{Nb} / \mathrm{AlO}_{\mathrm{x}}-\mathrm{Al} / \mathrm{Nb}$ structures deposited by the electron beam method were presented in [5]. Anodization profiles for multilayer structures deposited by the magnetron method is given in Fig.2. Niobium and aluminium films were deposited in oil-free vacuum, by constant current magnetron system. For pressure in the chumber. was $\mathrm{P}=2.5 \cdot 10^{-5} \mathrm{~Pa}$, argon pressure in depositing was $\mathrm{P}_{\mathrm{Ar}}=4 \cdot 10^{-1} \mathrm{~Pa}$. Fig.2, a gives anodization profile of the structure for which the rate of niobium deposition was $0.9 \mathrm{~nm} / \mathrm{s}$, thermal aluminium oxide obtained under $\mathrm{P}_{\mathrm{O} 2}=133 \mathrm{~Pa}$, oxidation time $\mathrm{t}=45 \mathrm{~min}$. There is a conciderable smearing of slopes of the barrier peak on the anodization profile. At the boundary between bottom niobium and aluminium there is observed the explicit fair minimum. If the rate of niobium film deposition 
increased to $5 \mathrm{~nm} / \mathrm{s}$, the smearing of the boundary considerably decreases (Fig.2,b). A plateau corresponding to anodization of continuous aluminium film appears clealy, the oxide peak is expressed more clearly than on curve a. The minimum at the boundary between bottom niobium and aluminium becomes substantially sharper and deeper, the value of minimum depends upon the thickness of the

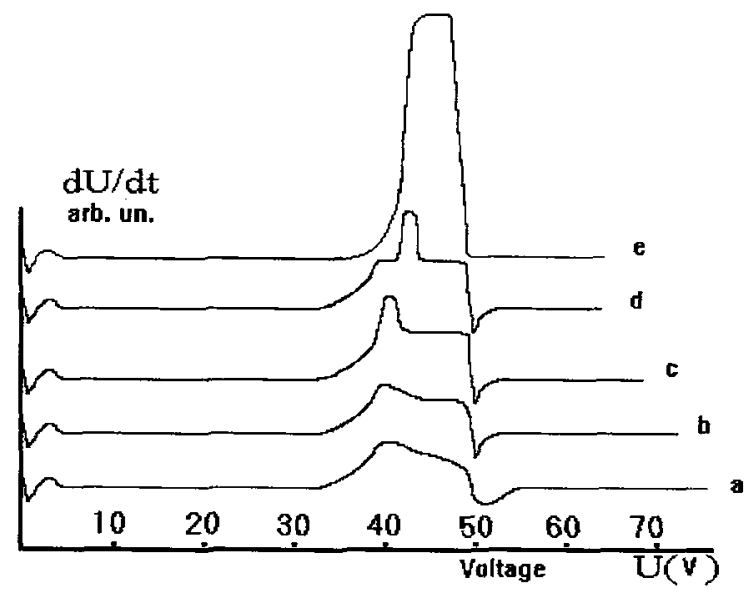

Figure 2. Anodization profiles of multilayered structures based on niobium and aluminium: oxidation;

$\mathrm{b}-\mathrm{Nb} / \mathrm{AlO} \mathrm{O}_{\mathrm{x}}-\mathrm{Al} / \mathrm{Nb}$, magnetron deposition, thermal oxidation; c - $\mathrm{Nb} / \mathrm{AlO} \mathrm{O}_{\mathrm{x}}-\mathrm{Al} / \mathrm{Nb}$, magnetron deposition, ion oxidation; $\mathrm{d}-\mathrm{Nb} / \mathrm{Al}-\mathrm{AlO}_{\mathrm{x}}-\mathrm{Al} / \mathrm{Nb}$, magnetron deposition, thermal oxidation;

e $-\mathrm{Nb} / \mathrm{AlO}_{x} / \mathrm{Nb}$, electron beam evaporation of all layers $\mathrm{a}-\mathrm{Nb} / \mathrm{AlO}_{\mathrm{x}}-\mathrm{Al} / \mathrm{Nb}$, electron beam deposition, thermal

\section{aluminium film.}

Obviously that the presence of transitions regions of the barrier layer corresponds to the volt-ampere characteristic with the low value of superconducting gap and its considerable smearing and also to high leakage currents, a small quality parameter $\mathrm{Rj} / \mathrm{Rn}$. The conducted investigations have shown that the presence of sharp boundaries between tunnel barrier and elecrtrodes on anodization profile corresponds to low leakage currents, a high parameters of Josephson junctions. The superconducting gap of such junctions has a value close to the theoretical one.

It is clear from the above mentioned that the increase of niobium deposition rate which resulted in obtaining films of more high purity and more dense packaging, positively influences on the structure of barrier region and leads to the enhancement of volt-ampere characteristics of Josephson junctions. $\mathrm{Nb} / \mathrm{Al}-\mathrm{AlO} \mathrm{O}_{\mathrm{x}} \mathrm{Al} / \mathrm{Nb}$ were deposited by means of the magnetron method under the following conditions: preliminary vacuum $2.5 \cdot 10^{-5} \mathrm{~Pa}$, argon pressure under deposition $4 \cdot 10^{-1} \mathrm{~Pa}$, rate of niobium films deposition $0.6 \mathrm{~nm} / \mathrm{s}$, of aluminium $2 \mathrm{~nm} / \mathrm{s}$. Aluminium film oxidation was realised thermally. We can clearly see two aluminium plateaus and the oxidation peak between them at $\mathrm{Nb} / \mathrm{Al}-$ $\mathrm{AlO}_{\mathrm{x}}-\mathrm{Al} / \mathrm{Nb}$ structures anodization profiles (Fig.2,d). The front of aluminium plateau is observed even when the voltage value corresponding to $\mathrm{Al}$ is $8 \mathrm{~V}$. We did not succeed in observing the aluminium plateau in structures $\mathrm{Nb} / \mathrm{AlO}_{\mathrm{x}}-\mathrm{Al} / \mathrm{Nb}$ with such a little thickness of aluminium film. This in itself is testimony to the high degree of smoothness of the aluminium oxide and the aluminium on it. It is interesting also to note that the altitude of the oxide peak is much more in this case than for $\mathrm{Nb} / \mathrm{AlO} \mathrm{x}^{-}$ $\mathrm{Al} / \mathrm{Nb}$ structures. The oxide damages underaluminium deposition on it is, probably, much less than under niobium deposition.

The $\mathrm{Nb} / \mathrm{Al}_{2} \mathrm{O}_{3} / \mathrm{Nb}$ structures were studied all the layers of which were deposited by means of electron beam method (the preliminary vacuum is $5 \cdot 10^{-5} \mathrm{~Pa}$, rate of deposition of niobium films is $0.7 \mathrm{~nm} / \mathrm{s}$, of $\mathrm{Al}_{2} \mathrm{O}_{3}$ films - $2 \mathrm{~nm} / \mathrm{s}$ ). $\mathrm{Al}_{2} \mathrm{O}_{3}$ with the purity of 99.99 was the initial material. It is obvious from the anodization profiles (Fig. 2,e ) that the peak altitude of $\mathrm{Al}_{2} \mathrm{O}_{3}$ is 10 more than in the case of thermal aluminium oxidation. The thickness of deposited oxide films was calculated by means of the formula $\mathrm{d}_{\mathrm{ox}}=\Delta \mathrm{UK}_{\mathrm{ox}}$ where $\Delta \mathrm{U}$ is a peak-to-peak value, $\mathrm{K}_{\mathrm{ox}}=1.3 \mathrm{~nm} / \mathrm{V}$ and makes up $20-30 \mathrm{~nm}$.

\subsection{Investigation of Structures with Thermal and Ion Oxide}

Fig. 2,c and 2,d give the profiles of structures anodizing differing only in obtaining of tunnel aluminium oxide: thermal oxidation $\left(\mathrm{P}_{\mathrm{O} 2}=133 \mathrm{~Pa}, \mathrm{t}=60 \mathrm{~min}\right)$ and ion oxidation $\left(\mathrm{P}_{\mathrm{O} 2}=1.33 \mathrm{~Pa}, \mathrm{t}=10 \mathrm{~s}\right)$. We consider 
that the difference of the altitude of peaks when using different methods of oxidation is connected with different degree of nonstoichoimetricity of oxides.

If we represent the formula of $\mathrm{AlO}_{\mathrm{x}}$ oxide in the form $\mathrm{Al}_{2} \mathrm{O}_{y-z}$ where $z$ is a degree of nonstoichoimetricity, then from the formula (4) we obtain for two initial oxides with the degree of nonstoichoimetricity $z_{1}$ and $z_{2}$

$$
(d U / d t)_{1^{\prime}} /(d U / d t)_{2}=z_{2} / z_{1}
$$

In such a manner, the comparison of maximal values dU/dt of thermal and ion oxides (Fig. 2, c, d) shows that the degree of nonstoichoimetricity under thermal oxidation is twice as much as in the case of ion one.

\section{ANODIZATION OF EDGES}

The anodizing of edges is one of the most critical operationin when the Josephson microcircuits fabricated by our method of two-stage anodization (TAP-process) [5,7]. The geometry of layers overlapping and quality of interlayer isolation near the edge determine the occurrence of microshortcircuits, the value of leakage currents, the area of Josephson contacts.

It is very difficult to control such a parameter as undercutting value while forming the picture of three-layer tunnel structure by liquid etching. In practice, the under cutting value for $\mathrm{Nb} / \mathrm{AlO} \mathrm{x}-\mathrm{Al} / \mathrm{Nb}$ structures of about $0.4 \mu \mathrm{m}$ thick varies from $0.5 \mu \mathrm{m}$ to $1.5 \mu \mathrm{m}$. The process of obtaining the isolating anodic oxide on the edge also depends on many factors. Among them it is worth noting the thermal photoresist treatment after etching and geometry of the edge after etching and such characteristics of anodizing process such as composition and temperature of an electrolyte, anodizing current density, voltage and time of formation.

We have developed the method of controlling the edge anodizing by way of recording the $\mathrm{dU} / \mathrm{dt}$ characteristics during anodic oxidation. Due to the small value of anodizing area (it was $4 \cdot 10^{-5} \mathrm{~cm}^{2}$ for structure thickness of $0.4 \mu \mathrm{m}$ ) it was necessary to create the special low-noise current and voltage with 0.3-0.1 mA current providing the anodizing current density of $1 \mathrm{~mA} / \mathrm{cm}^{2}$. The standard electrolyte based on ammonium pentaborate and ethylene glycol was used for anodic treatment of the edges. Anodizing was performed by a "drop" method, the after etching photoresist FP 051-MK served as a self-udjustment mask. The photoresist was additionally tanned at $140^{\circ} \mathrm{C}$ during 30 minutes at the air. The edge's area was subjected to anodic treatment by the "drop" up to the voltage 30-80 V. Formation by voltage was not carried out because peeling-off of photoresist was

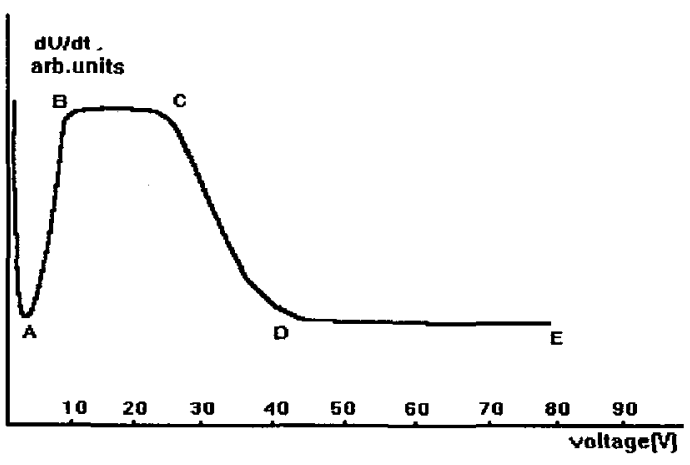

Figure 3 The anodization profile of the structure $\mathrm{Nb} / \mathrm{AlO}_{\mathrm{X}}-\mathrm{Al} / \mathrm{Nb}$ edge using photoresist mask observed while doing it.

Fig. 3 gives a tipical profile of anodization the edge area of $\mathrm{Nb} / \mathrm{AlO}-\mathrm{Al} / \mathrm{Nb}$ structure.It is seen from the figure that similar to anodizing the planar areas, the anodization profile has the initial minimum whose depth and width depend on the modes of photoresist treatment, the modes of structure etching and the quality of masks. We believe that minimum carries information on the edge's degree of waveness. As in the case of planar areas, one can observe the smoothing effect during anodic treatment of the edge with welldeveloped relief (Fig. 3, section $\mathrm{AB}$ ). The flange $\mathrm{BC}$ in Fig. 3 corresponds to anodizing of the edge proper of the patterned structure $\mathrm{Nb} / \mathrm{AlO} \mathrm{x}-\mathrm{Al} / \mathrm{Nb}$.

We observed the oxidation rate droping on $\mathrm{CD}$ section caused by expansion of the anodizing area due to 
penetration of electrolyte under photoresist. The voltage growth rate output to the flange $\mathrm{DE}$ testifies to occurence of the constant with respect to area front of anodic treatment.

Since the value of $\mathrm{dU} / \mathrm{dt}$ is inverselly proportional to anodizing area, so the relation $(\mathrm{dU} / \mathrm{dt})_{\mathrm{BC}} /(\mathrm{dU} / \mathrm{dt})_{\mathrm{DE}}$ gives possibility to calculate the ratio of areas of the edge and subanodization region and also to culculate the value of undercutting after chemical ething.

\section{SUMMARY}

The conducted studies show that by using of anodization spectroscopy as express-control method we can study a wide spectrum of characteristics of cryoelectronic thin-film structures on the basis of niobium and aluminium. By means of this method we found that:

the areas of homogeneous thickness deposited by constant current magnetron deposition of films depend on the design features of deposition system;

the decrease of temperature of superconducting junctions of niobium films under the increase of argon pressure during the process of magnetron deposition is connected both with the enrichment of films by oxigen and other impurities and with the increase of their porosity;

the surface roughness and porosity of niobium films depends on argon pressure under deposition and on deposition rate;

the continuity of aluminium film in Josephson tunnel structures $\mathrm{Nb} / \mathrm{AlO}_{\mathrm{x}}-\mathrm{Al} / \mathrm{Nb}$ deposited by electronbeam method is observed with the thickness about $25 \mathrm{~nm}$ and under magnetron deposition with the thickness of $10 \mathrm{~nm}$;

the degree of nonstoichoimetricity of the oxide layer in multilayered film structure is inversely proportional to the value $\mathrm{dU} / \mathrm{dt}$ of this layer on the anodization profile;

the stoichoimetricity of the aluminium oxide in $\mathrm{Nb} / \mathrm{AlO} \mathrm{x}_{\mathrm{x}}-\mathrm{Al} / \mathrm{Nb}$ structures is higher under ion oxidation that the thermal one;

the methods developed by us for controlling the edges oxidation make it possible to control the area drift due to subetching and subanodization directly in process of microcircuits fabrication as well as to determine the value of the necessary correction for the photomasks.

\section{References}

[1] Imamura T., Hasuo S., IEEE Trans. Magn. 25(1989) 1131-1134.

[2] Imamura T., Hasuo S., IEEE Trans. Magn.27(1991) 3172-3175.(1989) 732-734.

[3] Blamire M. G. et al. Appl. Phys. Lett. 55(1989) 732-734.

[4] Vojtovich I.D., Lebedeva T.S., Navala S.Ya., Cryogenics ICEC Supplement 32 (1992), 579.

[5] Lebedeva T.S., Navala S.Ya. Phisical-technological design in the field of computer technique, (Cybernetic Institute by V.M. Glushkov, Kiev, 1990) pp.72-80.

[6] Vojtovich I.D., Kolesnik Yu. S., Lebedeva T.S., Navala S. Ya. "Express-control of thin-film SQUID Production by Anodization Spectroscopy." EUCAS'93 Proc., Gottingen.-1993.- p.139

[7] Lebedeva T.S. et al., Superconductive electronics and biomagnetism, (Cybernetic Institute by V.M. Glushkov, Kiev, 1995) pp.24-33.

[8] Lebedeva T.S., Shpilevoy P.B., Superconductive electronics and biomagnetism, (Cybernetic Institute by V.M. Glushkov, Kiev, 1995) pp.33-38. 